\title{
A simplified approach for the historical analysis of urban person travel
}

\author{
Amer S. Shalaby
}

\begin{abstract}
This paper presents a simplified approach to quantify the contribution of individual factors to the historical growth or decline in total travel between two points in time. The method employs person trip rates and distributions of the individual characteristics at the two time points to determine the portion of urban person travel increase or decrease associated with the change in each factor. The paper presents the application of the approach to investigate changes in person travel in the Greater Toronto Area between 1986 and 1996. Specifically, the study determined the change in person travel attributed to each of the following factors independently: change in population size, change in age distribution, change in residential location distribution, and change in employment status distribution (full time, part time, work at home). The data were obtained from the 1986 and 1996 Transportation Tomorrow Surveys (TTSs).
\end{abstract}

Key words: transportation planning, travel demand.

Résumé : Cet article présente une approche simplifiée afin de quantifier la contribution des facteurs individuels à l'augmentation/diminution historique du nombre total de voyages entre deux points dans le temps. La méthode utilise les taux de déplacements des individus et les distributions des caractéristiques individuelles aux deux points dans le temps afin de déterminer l'augmentation/diminution de la portion des déplacements des individus en ville associée au changement de chaque facteur. Ensuite, l'article présente l'application de l'approche afin d'étudier les changements des déplacements des individus dans le Grand Toronto entre 1986 et 1996 . Plus particulièrement, l'étude a déterminé que le changement dans les déplacements des individus est attribué à chacun de ces facteurs indépendants, soit le changement dans la taille de la population, le changement dans la distribution de l'âge, le changement dans la distribution des locations résidentielles et le changement dans la distribution du statut d'emploi (temps plein, temps partiel, travail à la maison). Les données ont été obtenues dans le Transportation Tomorrow Surveys (TTS) de 1986 et 1996.

Mots clés : planification des transports, demande de déplacements.

[Traduit par la Rédaction]

\section{Introduction}

The growth or decline in urban person travel over time is usually a result of the temporal change in population size and the temporal changes in the composition of that population (e.g., age distribution, spatial distribution of population, composition of the workforce with respect to employment status). The temporal changes in such factors occur simultaneously, and it is thus difficult to quantify the contribution of each factor to the overall change in person travel. Determining the contribution of each factor is very important for a better understanding of key contributors and their role in travel growth or decline in urban areas and for better planning of required transportation infrastructure and services.

Shalaby (1998a) isolated the role and contribution of transportation service characteristics to the work-trip mode

Received 26 February 2002. Revision accepted 11 July 2002. Published on the NRC Research Press Web site at http://cjce.nrc.ca on 10 September 2002.

A.S. Shalaby. Department of Civil Engineering, University of Toronto, 35 St. George St., Toronto, ON M5S 1A4, Canada (e-mail: amer@ecf.utoronto.ca).

Written discussion of this article is welcomed and will be received by the Editor until 28 February 2003. choice. The study showed that only $16-23 \%$ of the work-trip mode choice is explained by the relative level-of-service characteristics. Other demographic and socioeconomic factors account for the remaining variability in mode choice, indicating the significance of such factors in determining travel demand. Typical of similar research, the study was based on data from one cross-sectional survey and focused on work-trip mode choice only, and the analysis is therefore not readily transferable for investigating contributions of individual factors to overall travel changes over time.

Even though existing frameworks for urban transportation modeling, such as the aggregate four-stage urban transportation modelling system (UTMS) and the disaggregate framework proposed by Akiva (1974), are conceivably capable of assessing the historical changes in total urban person travel and the contribution of major factors to such changes, they require a very significant modeling and analysis effort to make such an assessment. With the increasing availability of cross-sectional travel data for several time points in the same urban area (e.g., the Transportation Tomorrow Survey (TTS) conducted in the Greater Toronto Area (GTA) every 5 years since 1986) there is a growing need for more simplified methods to assess historical changes in overall travel and to determine the key factors responsible for such changes.

Pickrell and Schimek (1997) decomposed growth in vehicle miles travelled (VMT) into smaller components to deter- 
mine the sources of growth in household travel. The approach, however, does not explicitly address shifts in individual variable distributions and the effect of these shifts on travel growth.

This paper presents a simplified approach to quantify the contribution of individual factors to the growth or decline in total travel between two points in time. The method employs person trip rates and distributions of the individual factors at the two time points to determine the portion of person travel increase or decrease associated with the change in each factor. The paper presents the application of the approach to investigate changes between 1986 and 1996 in person travel in the GTA, which is shown in Fig. 1. Specifically, the study determined the change in person travel attributed to each of the following factors: change in population size, change in age distribution, change in residential location distribution, and change in employment status distribution (full time, part time, work at home). The data were obtained from the 1986 and 1996 TTSs. This paper is based on a study that investigated trends in travel behaviour and the key travel-related factors (Shalaby 1998b, 1986c).

\section{Approach}

The change in the number of trips during a period (e.g., 5 years) can be separated into two components: change related to population increase or decrease, and change related to change in trip-making rate (i.e., number of daily trips per person). The trip-making rate is related in part to the personal and household characteristics of the urban residents and to other characteristics of the transportation and urban activity systems. For example, a middle-aged person makes more trips per day than an elderly person, all else being equal. Similarly, a person with a driver's license and an available car makes more trips per day than a person without a car, all else being equal. Therefore, the trip-making rate changes over time in part as a result of changes in the composition of the population caused by shifts in the population distributions (e.g., age distribution, residential location distribution, employment status distribution). Even if the distributions of all travel-related factors do not change over time, however, the trip-making rate might not remain the same.
Fig. 1. The Greater Toronto Area (GTA).

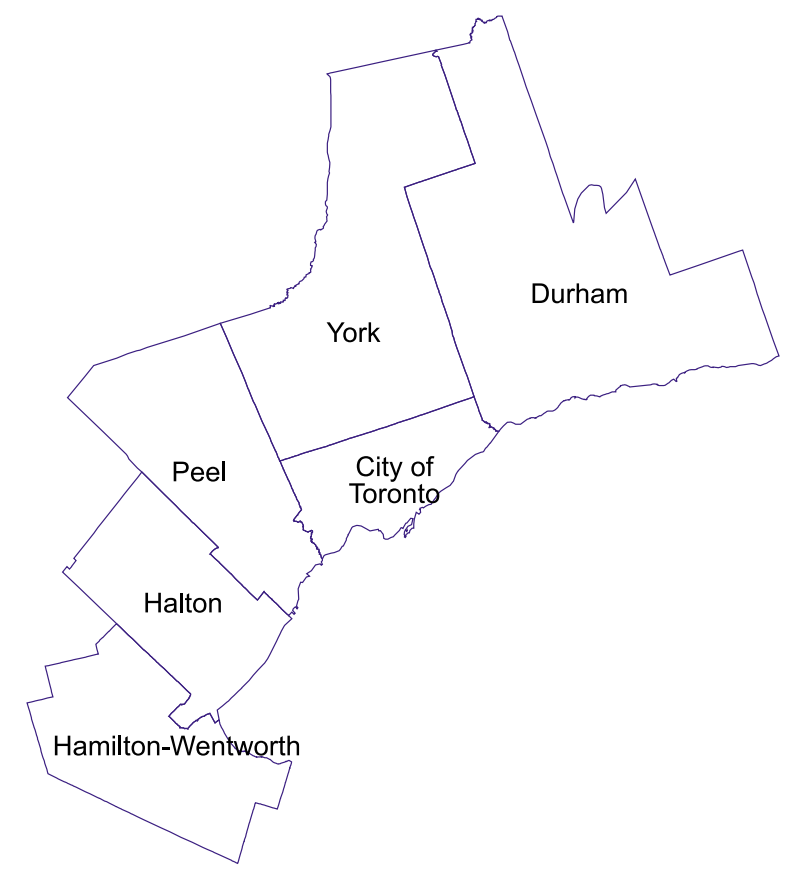

This is because two persons at different points in time (say 1986 and 1991) with exactly the same characteristics could have different daily trip rates due to personal travel idiosyncrasies. For example, people with certain personal characteristics in 1986 (e.g., aged between 25 and 30 years) might carry over their travel habits to 1991 ; these people with their new characteristics in 1991 (then aged between 31 and 35 years) could have different travel habits from those who had the same personal characteristics in 1986. Therefore, the analysis presented in this paper seeks to decompose the change in the number of trips between two time points, say $t_{1}$ and $t_{2}$, into the change associated with population increase or decrease and the change associated with change in tripmaking rate, which reflects shifts in the distributions of travel-related factors and shifts in travel habits. The former component (i.e., change associated with population increase or decrease between $t_{1}$ and $t_{2}$ ) can be computed as

$$
\text { change }_{t_{1}-t_{2}}(\text { population })=\text { rate }_{t_{1}} \times \text { population }_{t_{2}}-\text { trips }_{t_{1}}
$$

In other words, it is the number of extra trips in $t_{2}$ over the $t_{1}$ trips if the population size only increases between $t_{1}$ and $t_{2}$, while the $t_{1}$ overall trip rate remains unchanged during the same period. Equation [1] can also be expressed as

$$
\begin{aligned}
\text { change }_{t_{1}-t_{2}} \text { (population) } & =\frac{\operatorname{trips}_{t_{1}}}{\text { population }_{t_{1}}} \times \text { population }_{t_{2}}-\operatorname{trips}_{t_{1}} \\
& =\operatorname{trips}_{t_{1}}\left(\frac{\text { population }_{t_{2}}}{\text { population }_{t_{1}}}-1\right)
\end{aligned}
$$

which represents the $t_{1}$ trips multiplied by the percent increase in population size. Therefore, it represents the increase in number of trips if their rate of change between $t_{1}$ and $t_{2}$ was similar to that of the population.

The second component of travel growth represents the change in daily trips associated with the change in the overall tripmaking rate. It can be expressed as 


$$
\begin{aligned}
\text { change }_{t_{1}-t_{2}}(\text { rate }) & =\operatorname{trips}_{t_{2}}-\text { rate }_{t_{1}} \times \text { population }_{t_{2}} \\
& =\operatorname{trips}_{t_{2}}-\frac{\operatorname{trips}_{t_{1}}}{\text { population }_{t_{1}}} \times \text { population }_{t_{2}} \\
& =\operatorname{trips}_{t_{1}} \times \frac{\text { population }_{t_{2}}}{\text { population }_{t_{1}}}\left(\frac{\operatorname{trips}_{t_{2}} / \text { population }_{t_{2}}}{\operatorname{trips}_{t_{1}} \text { population }_{t_{1}}}-1\right)
\end{aligned}
$$

which represents the $t_{2}$ trips assuming no change in trip rate (i.e., trips $t_{t_{1}} \times$ population $_{t_{2}} /$ population $_{t_{1}}$ ) multiplied by the percent increase in trip rate between $t_{1}$ and $t_{2}$.

Equation [3] represents the change in the number of trips associated with shifts in the distributions of all travel-related factors and shifts in travel habits, both of which are reflected in the overall trip rate change. Now, consider the change in the number of trips associated with the distribution shift of one variable only, say age. Suppose age is not correlated with any other travel-related variable and we have $n$ age cohorts. Suppose also that between $t_{1}$ and $t_{2}$ changes happened only in the population size and the distributions of other travel-related variables, while the age distribution remained the same. In such a scenario, the number of trips in $t_{2}$ would be

$$
\sum_{i=1}^{n}\left[\operatorname{population}_{t_{2}} \times \frac{\operatorname{population}_{t_{1}}(i)}{\operatorname{population}_{t_{1}}}\right] \times\left[\frac{\operatorname{trips}_{t_{2}}(i)}{\operatorname{population}_{t_{2}}(i)}\right]
$$

The first bracket in eq. [4] represents the population of age cohort $i$ if the age distribution in $t_{2}$ were the same as that in $t_{1}$. The second bracket represents the $t_{2}$ trip rate for age cohort $i$. The $t_{2}$ trip rate is used to reflect the distribution shifts of other variables. Equation [4] can be restructured as

$$
\sum_{i=1}^{n} \operatorname{trips}_{t_{2}}(i) \times \frac{\text { population }_{t_{1}}(i) / \text { population }_{t_{1}}}{\text { population }_{t_{2}}(i) / \text { population }_{t_{2}}}
$$

In words, the eq. [5] represents the number of trips in $t_{2}$ by persons in the age cohort $i$ multiplied by the ratio of the $t_{1}$ population share of age cohort $i$ to the $t_{2}$ share of the same cohort, summed over all age cohorts. The difference between the total number of trips in $t_{2}$ and eq. [5] would be attributed to the shift in age distribution, as shown in the following equation:

$$
\begin{aligned}
& \text { change }_{t_{1}-t_{2}} \text { (age) } \\
& =\operatorname{trips}_{t_{2}}-\sum_{i=1}^{n} \operatorname{trips}_{t_{2}}(i) \times \frac{\text { population }_{t_{1}}(i) / \text { population }_{t_{1}}}{\text { population }_{t_{2}}(i) / \text { population }_{t_{2}}}
\end{aligned}
$$

Two points merit some discussion here. First, the use of the $t_{2}$ trip rates reflects not only the distribution shifts of other variables but also differences in trip making between the same age cohort at different points in time, as noted earlier. For example, persons aged 35-40 years in $t_{1}$ may have different trip-making patterns than persons aged $35-40$ years in $t_{2}$, all else being equal. Therefore, the change in number of trips between $t_{1}$ and $t_{2}$ associated with the shift in age distribution, as calculated by eq. [6], reflects strictly the change associated with the shift in age distribution only during that period and does not include the effect of changes in travel habits.

The second point regards the assumption made earlier that age is not correlated with other travel-related variables. Obviously, this is a strong assumption, since age is expected to be correlated with factors such as driver's license and car ownership. This is a problem common to all analyses based on cross-sectional data (see Shalaby 1998a for a detailed discussion of this issue). Therefore, in this analysis, any change in trips associated with a shift in an individual variable distribution is attributed primarily to that variable and to other correlated variables. Even though limited by the lack of explicit treatment of correlation between variables, the simplified approach presented in this paper is still useful and produces plausible results as shown later. The approach is particularly useful for assessing relative contributions of variables. The use of panel data is better suited for the treatment of correlation between variables, but was beyond the scope of this study. Future research to improve this approach should address the issue of correlation between variables, possibly using panel data.

Equations [2], [3], and [6] were used to develop estimates of the change in the number of GTA trips associated with the population increase, change in overall trip rate, and individual shifts of three distributions between 1986 and 1996. The three distributions are for the variables age, residential location, and employment status. The number of trips examined here includes the total number of trips, number of trips by purpose, and number of trips by travel mode. The variables investigated in this paper are used only to demonstrate the application of the approach developed in this study and are not meant to represent all relevant travel-related variables. Other investigated variables (not included in this paper) can be found in Shalaby (1998c).

\section{Effect of changes in population size and trip rate}

The GTA population of age 11 years or above (i.e., those surveyed in the TTSs) increased from 3.46 million in 1986 to 4.16 million in 1996 , representing a $20 \%$ increase. The total number of daily trips made by that population increased from approximately 8 million in 1986 to 9.9 million in 1996, representing a $24 \%$ growth in person travel. These changes are reflected in the daily trip-making rate (i.e., number of trips per person), which increased from 2.31 trips per person in 1986 to 2.38 trips per person in 1996, as shown in Fig. 2. Figure 2 also shows that the number of home-based work trips per person declined while each of the home-based discretionary (i.e., home-based other) and non-home-based trip 
Fig. 2. Daily trip rate by purpose and mode.

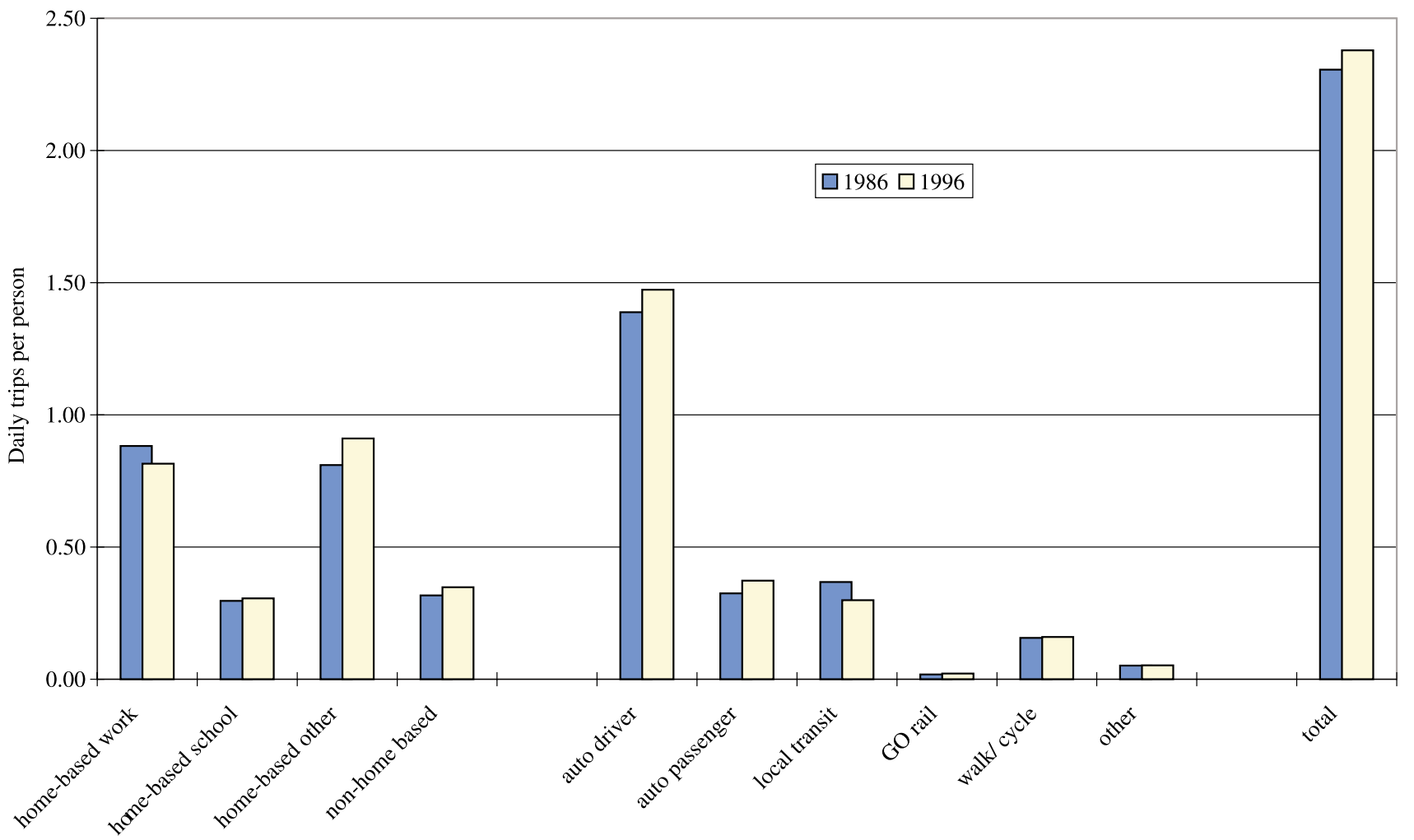

Fig. 3. Travel changes associated with population growth and shift in overall trip rate.

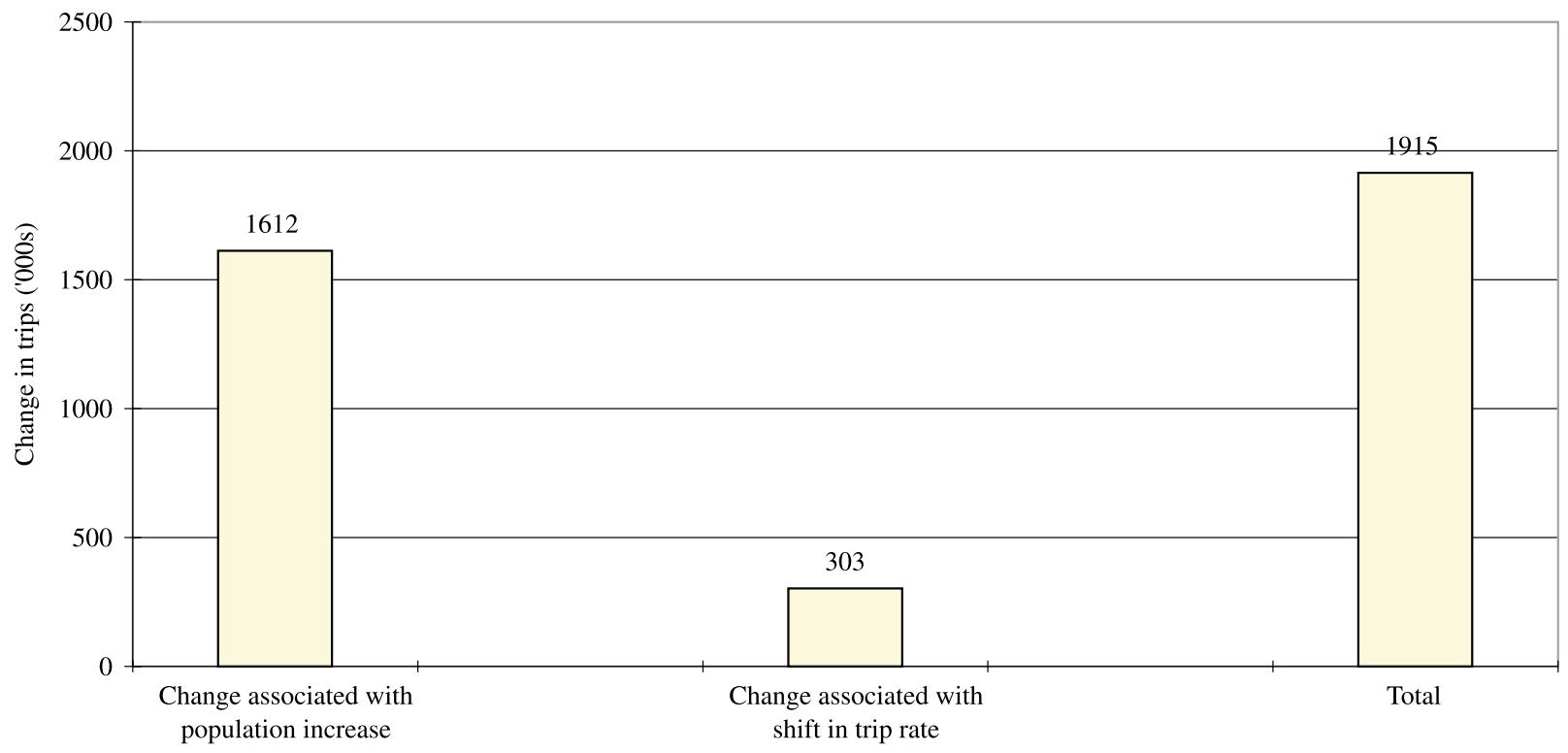

rates increased during the 10 -year period. With respect to travel mode, the exhibit shows that the number of daily transit trips per person declined from 0.37 in 1986 to 0.30 in 1996. During the same period, both trip rates for the autodriver and auto-passenger modes increased.

Figure 3 shows the relative impacts of changes in population size and trip-making rate on travel growth. The population growth alone resulted in an extra 1.61 million trips per day between 1986 and 1996 while the increase in the overall trip rate during the same period (caused largely by changes in population composition and travel habits) resulted in an extra 0.3 million trips per day. This indicates the far smaller contribution to travel growth of population composition shifts compared with population growth in the GTA.

Figure 4 shows the above changes disaggregated by trip purpose. The population increase between 1986 and 1996 resulted in a larger increase in home-based work and homebased discretionary trips (each type increased by about 0.6 million daily trips) than home-based school and nonhome-based trips (around 0.2 million extra trips each). As a 
Fig. 4. Travel changes by trip purpose.

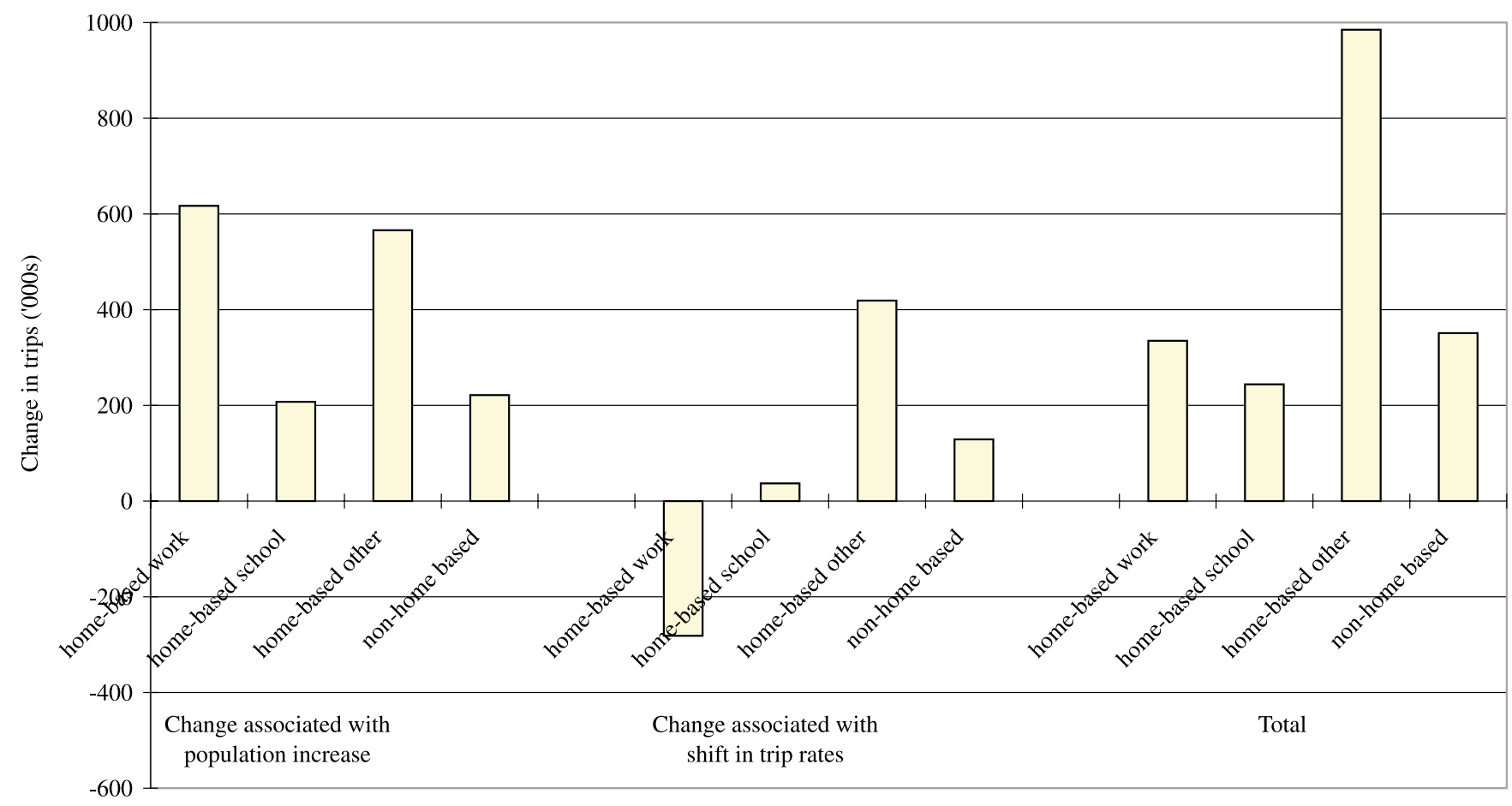

Fig. 5. Travel changes by travel mode.

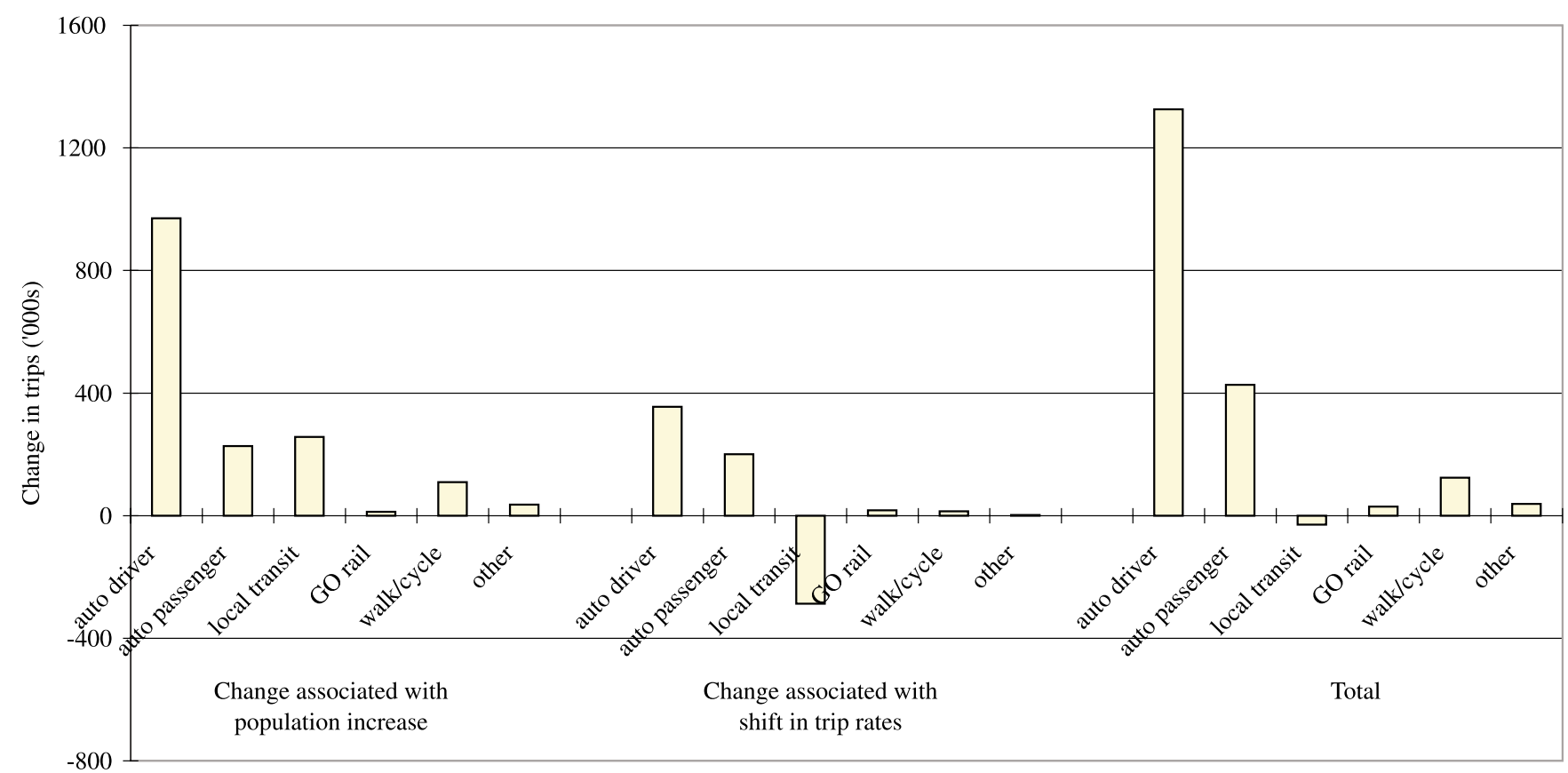

result of the drop in the home-based work-trip rate between 1986 and 1996, the number of home-based work trips associated with these changes declined, partially offsetting the growth in home-based work travel caused by population growth. The changes in trip rates of other trip purposes resulted in a more substantial increase in home-based discretionary trips than home-based school and non-home-based trips. Overall, the increase in home-based discretionary trips exceeded the growth in all other trip purposes combined.

Approximately 1 million auto-driver trips per day were introduced between 1986 and 1996 due to the population increase alone, as shown in Fig. 5. The corresponding number of auto-passenger trips was about 227 thousand, slightly less than the extra number of daily transit trips introduced due to 
Fig. 6. Age distribution of the GTA population.

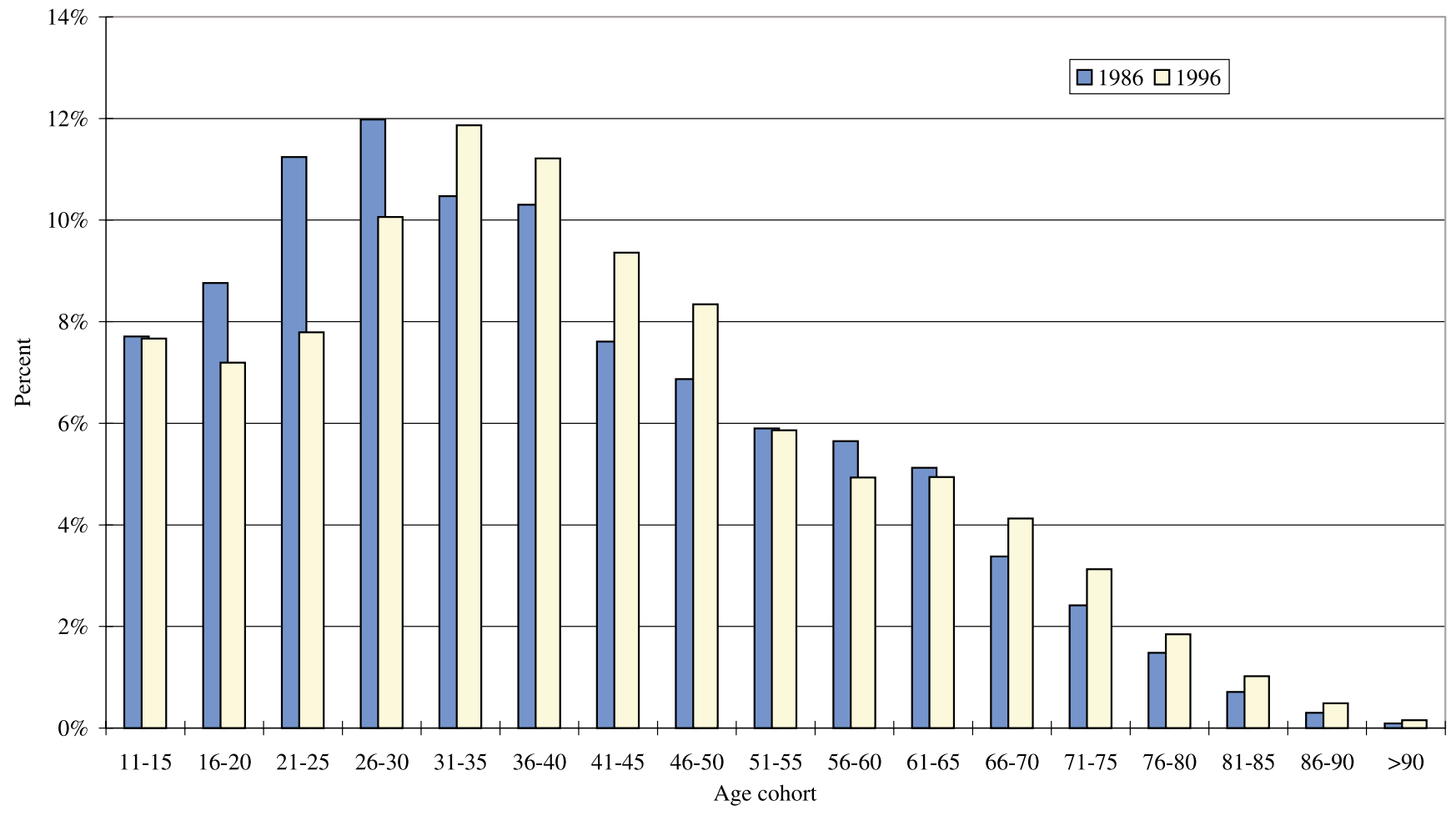

the population increase alone during the 10 -year period. The drop in transit trip rates, however, resulted in the reduction of the daily transit trips which balanced the increase in transit trips due to the population increase, with a net effect of an overall small decline of the daily transit trips. The increase in the auto-driver trip rate between 1986 and 1996 introduced an extra 0.35 million auto-driver trips per day. Similarly, the increase in auto-passenger trip rate resulted in an extra 0.2 million trips.

\section{Effect of age distribution shift}

Figure 6 shows the aging of the "baby boom" generation and its effect on the population age composition. The proportion of persons aged 16-30 years declined between 1986 and 1996 while the proportion of those aged 31-50 years and those aged 66 years or over increased during the same period. Figure 7 shows that overall trip rate of the persons aged 16-30 years is generally lower than that of the persons aged 31-50 years but higher than the trip rate of the persons aged 66 years and over. Consequently, minor changes occurred in the total number of trips in association with the shift in age distribution, as shown in Fig. 8. However, the number of trips of certain purposes and the number of trips made by specific travel modes changed substantially in association with the age distribution shift. For example, while the number of home-based school trips dropped substantially, mainly due to the lower proportion of persons aged 16-30 years who have higher home-based school trip rates than at later ages, the number of home-based discretionary trips increased, mainly due to the higher proportions of persons aged 31-50 years and 66 years and over who correspond to the two peaks of the home-based discretionary trip rate profile. Figure 8 also shows relatively small changes in home-based work and non-home-based trips associated with the age distribution shift.

The number of auto-driver trips increased substantially, while the numbers of auto-passenger, transit, and walk-cycle trips dropped, in association with the decline of the proportions of younger persons and the increase in the proportions of older persons.

\section{Effect of shift in residential location distribution}

Figure 9 shows the decline in the proportion of GTA residents living in Toronto from 54\% in 1986 to $48 \%$ in 1996. During the same period, the neighbouring lower density regions of Durham, York, and Peel experienced increases in the proportion of the GTA residents in each region.

Figure 10 shows that the trip-making rate is in general comparable across the GTA, with the residents of Toronto and Hamilton-Wentworth making slightly fewer trips per person than the residents of the other regions. The trip rates across the GTA increased slightly between 1986 and 1996.

As shown in Fig. 11, the number of trips for each purpose increased slightly in association with the increased proportion of GTA residents living outside Toronto. The number of auto-driver trips increased substantially between 1986 and 1996, however, while the number of transit trips declined in association with the shift in the residential location distribution. Minor changes happened in the number of trips by other travel modes in conjunction with the shift in the residential location distribution. These changes resulted in a net increase in the total number of trips of about 72000 between 1986 and 1996. 
Fig. 7. Trip making rate by age.

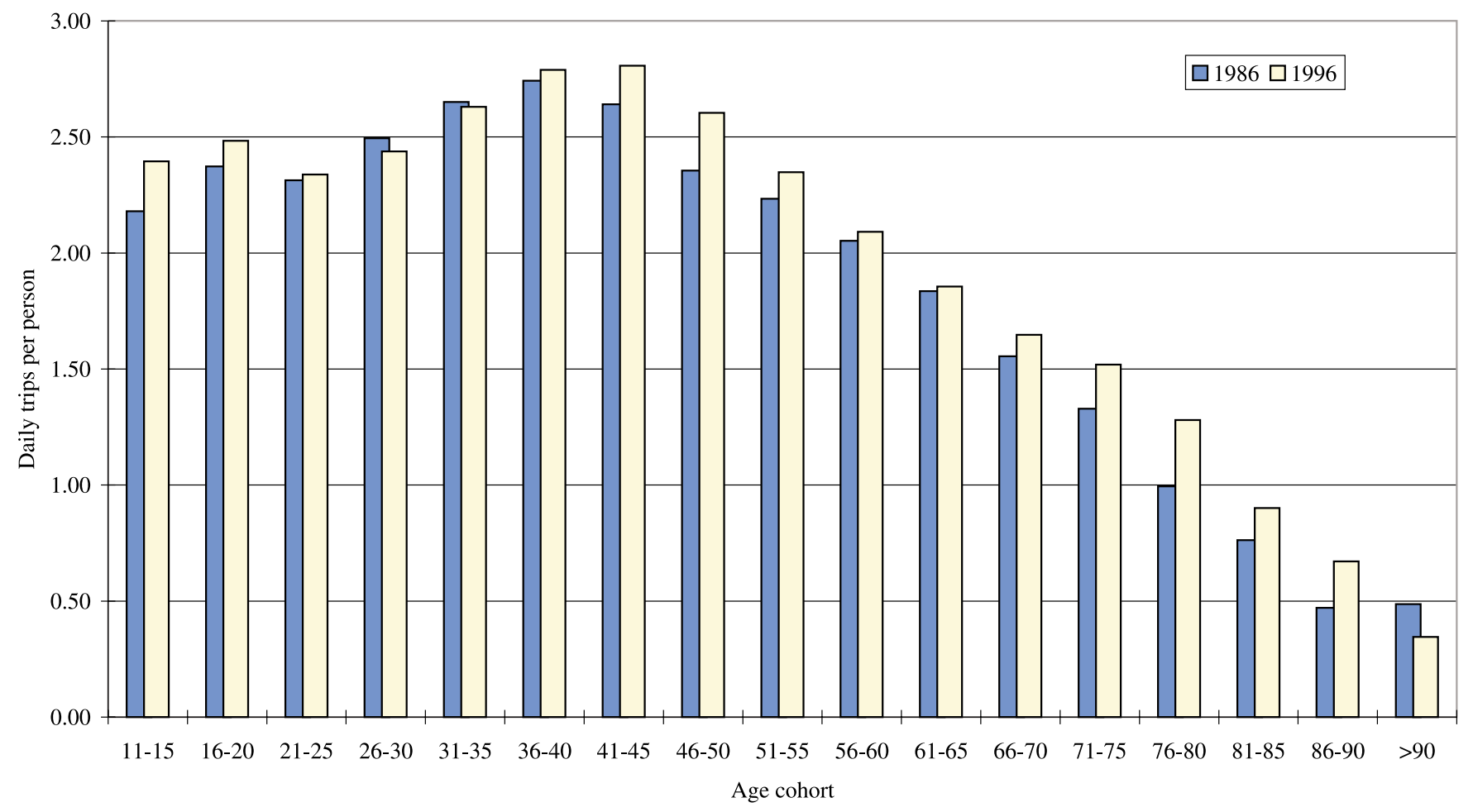

Fig. 8. Trip changes due to age distribution shift.

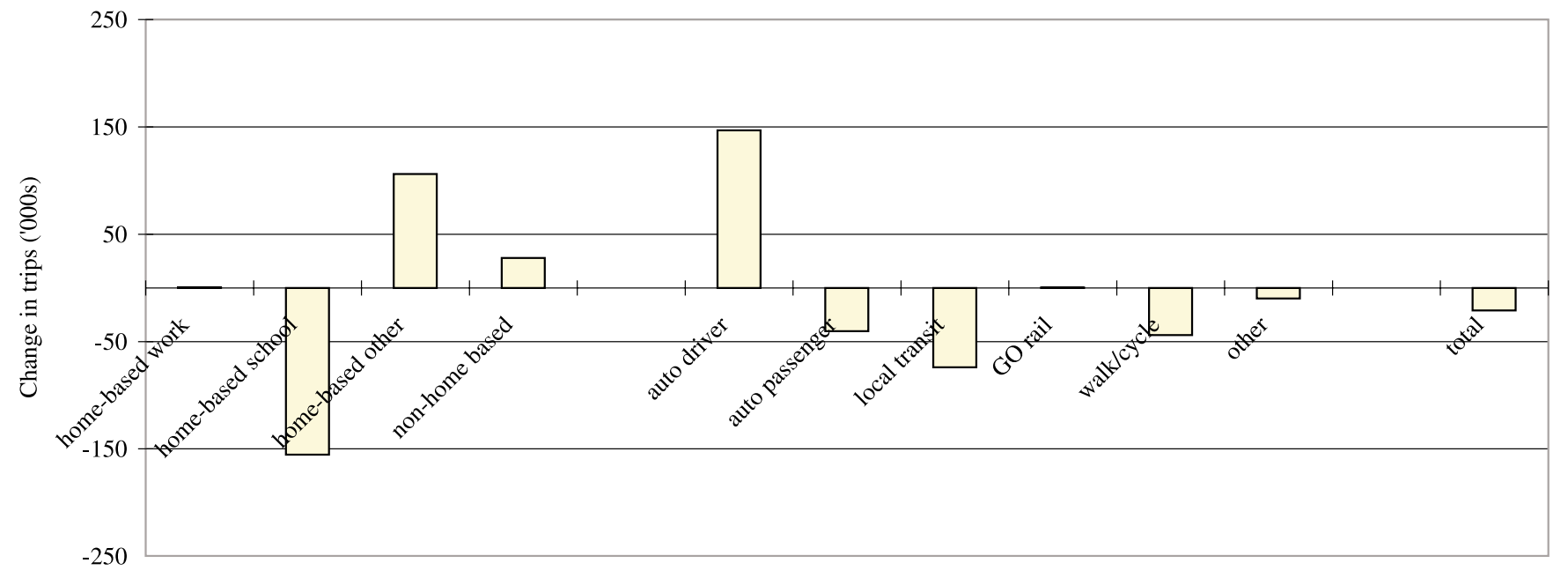

\section{Effect of shift in employment status distribution}

Figure 12 shows that the proportion of the full-time employed population dropped from $54 \%$ in 1986 to $46 \%$ in 1996, while the proportions of part-time and work-at-home employees changed slightly during the same period. The proportion of "other" persons, mainly unemployed or students, increased from 36\% in 1986 to $42 \%$ in 1996 . These changes were caused mainly by the economic recession that hit the GTA in the early 1990s.

Figure 13 shows that full-time and part-time workers make almost the same number of trips per person but make more trips per person than work-at-home workers, who in turn make more trips per person than non-workers. The trip rate of work-at-home workers experienced the largest increase between 1986 and 1996, almost 0.5 trips per person.

The decline of the proportion of full-time workers and the increased proportion of non-workers resulted in a substantial reduction in the number of home-based work trips (441 thousand trips between 1986 and 1996), a reduction in the number of non-home-based trips, and an increase in the number of home-based school trips and the number of home-based discretionary trips, as shown in Fig. 14. The number of auto-driver trips also declined substantially (by 351 thousand trips between 1986 and 1996), while the number of auto-passenger trips and the number of walk-cycle trips increased. Since the transit trip rates for full-time workers and non-workers are comparable, small changes happened in the number of transit trips in association with the 
Fig. 9. Residential location distribution. Ham-Went, Hamilton-Wentworth.

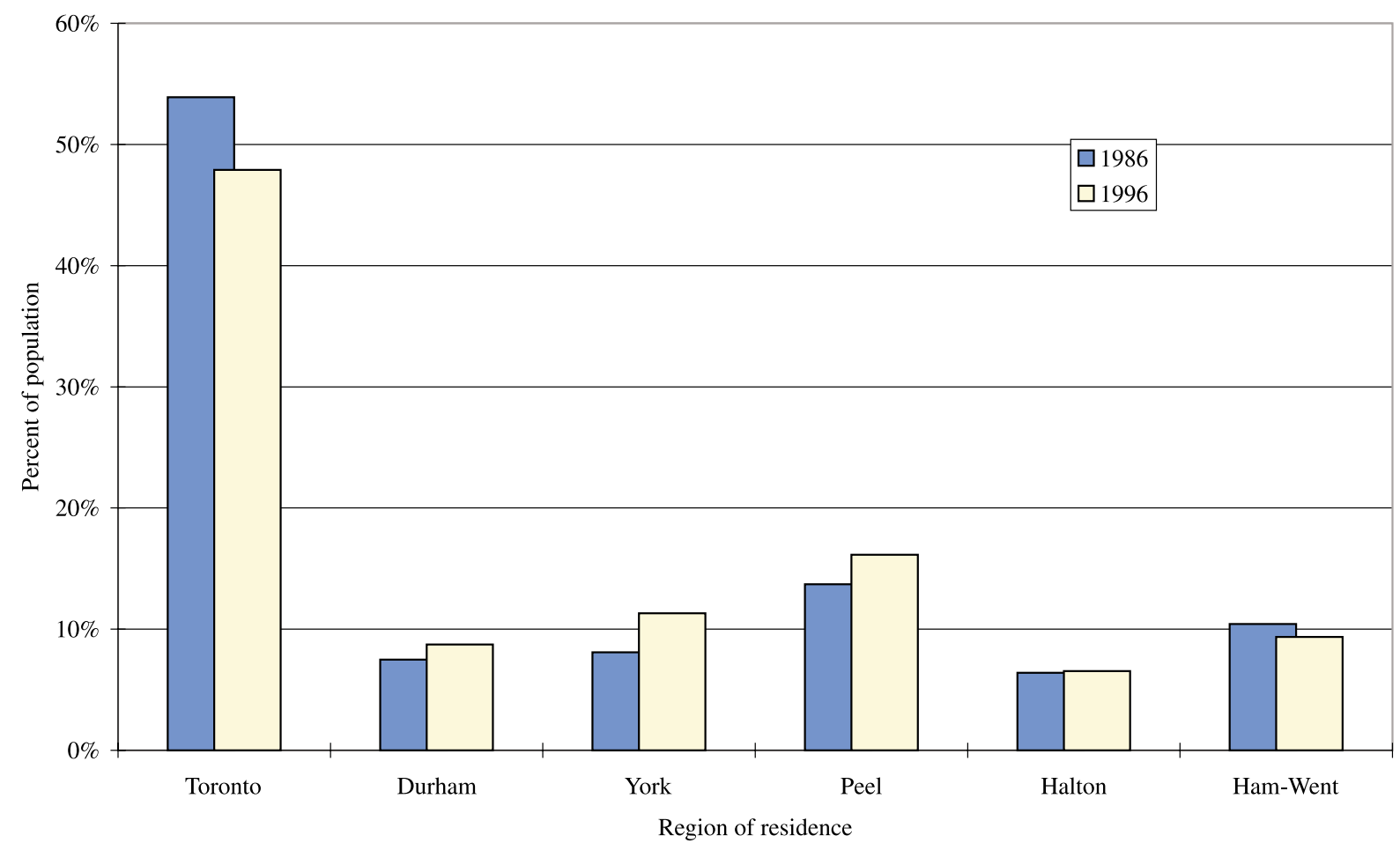

Fig. 10. Trip rate by residential location.

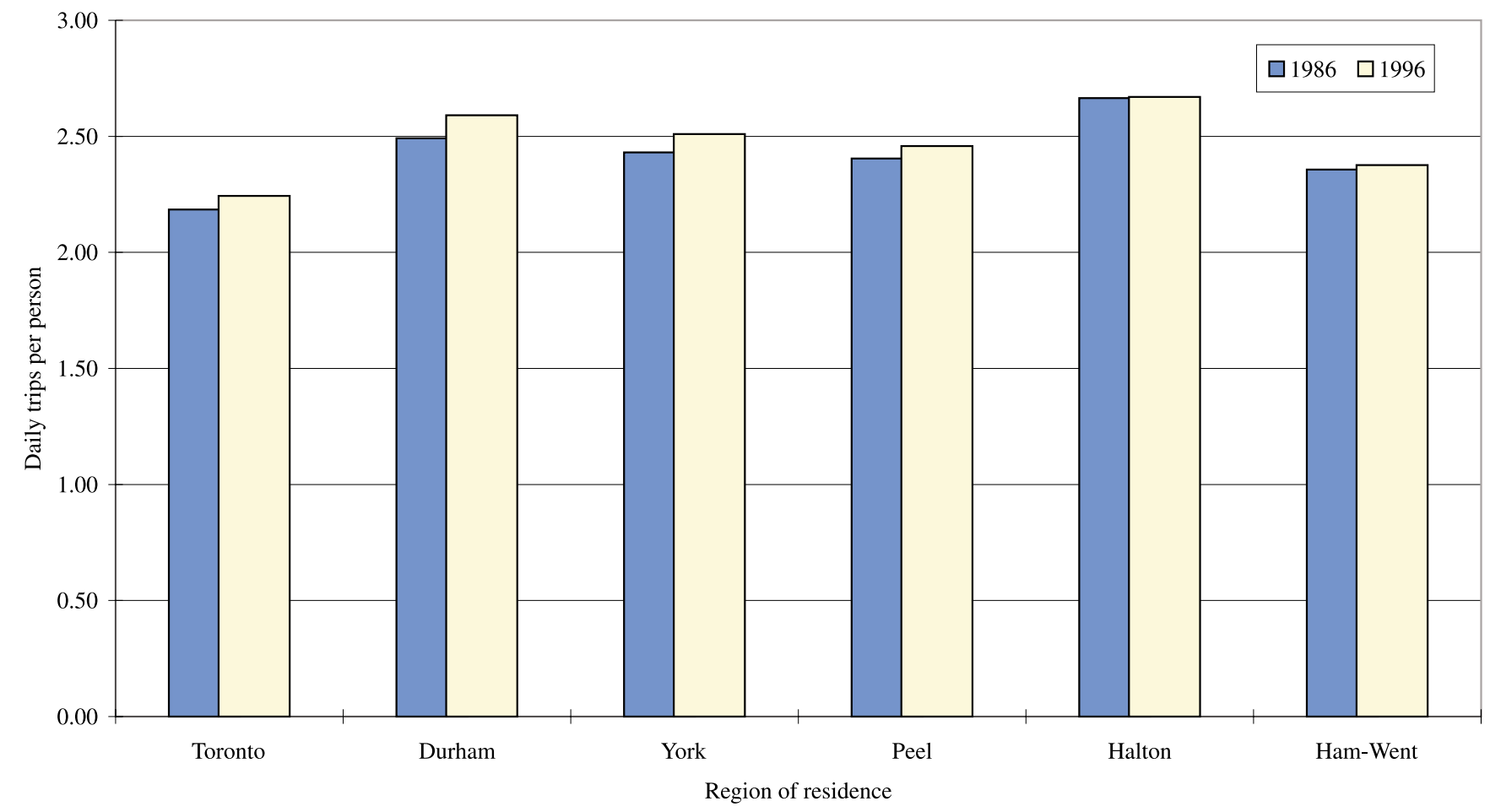

employment status distribution, as shown in Fig. 14. The above changes resulted in a net reduction in the total number of trips of 248 thousand between 1986 and 1996.

\section{Summary}

The study developed a simplified approach to assess individual contributions to travel growth. Even though the ap- proach has some limitations (which are typical of analyses and models based on cross-sectional data), it has produced plausible and useful results. For demonstration purposes, the approach has been applied to five factors, namely population growth, changes in overall trip rate, and individual shifts of three distributions. Table 1 summarizes the results. The following are a few observations: (1) population growth has resulted in much more travel than change in trip-making rate; 
Fig. 11. Travel changes due to shift in residential location distribution.

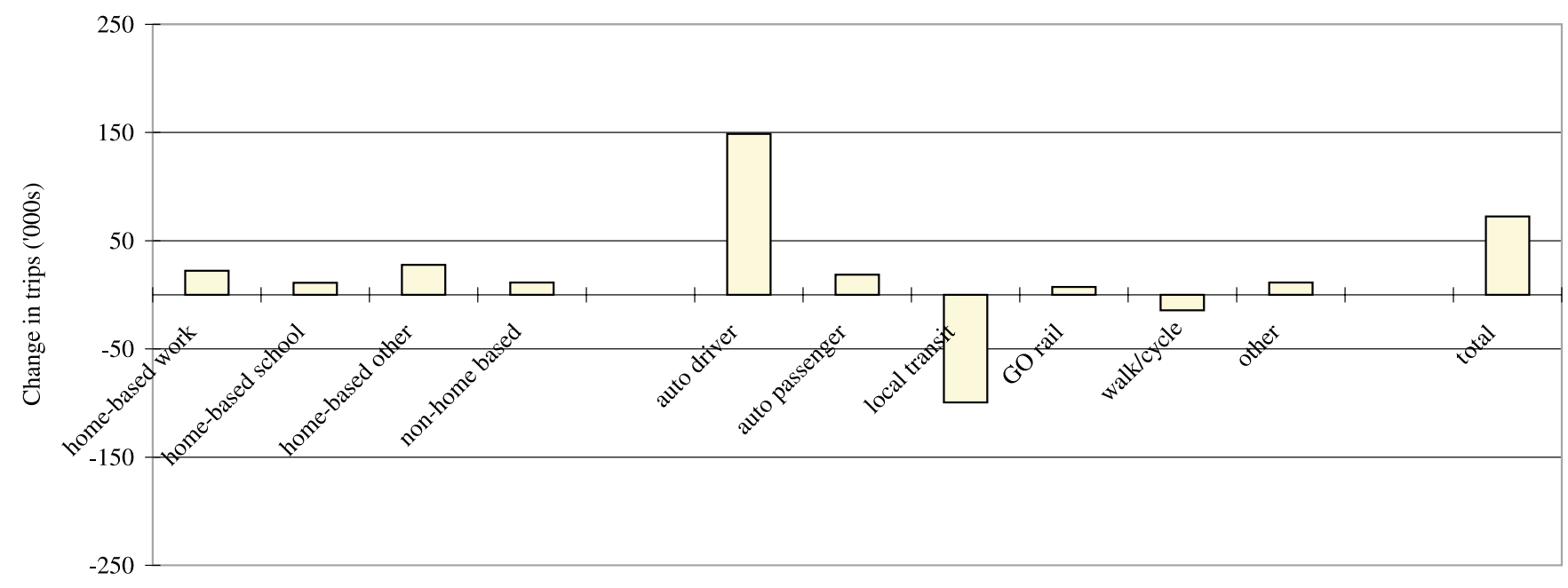

Fig. 12. Employment status distribution.

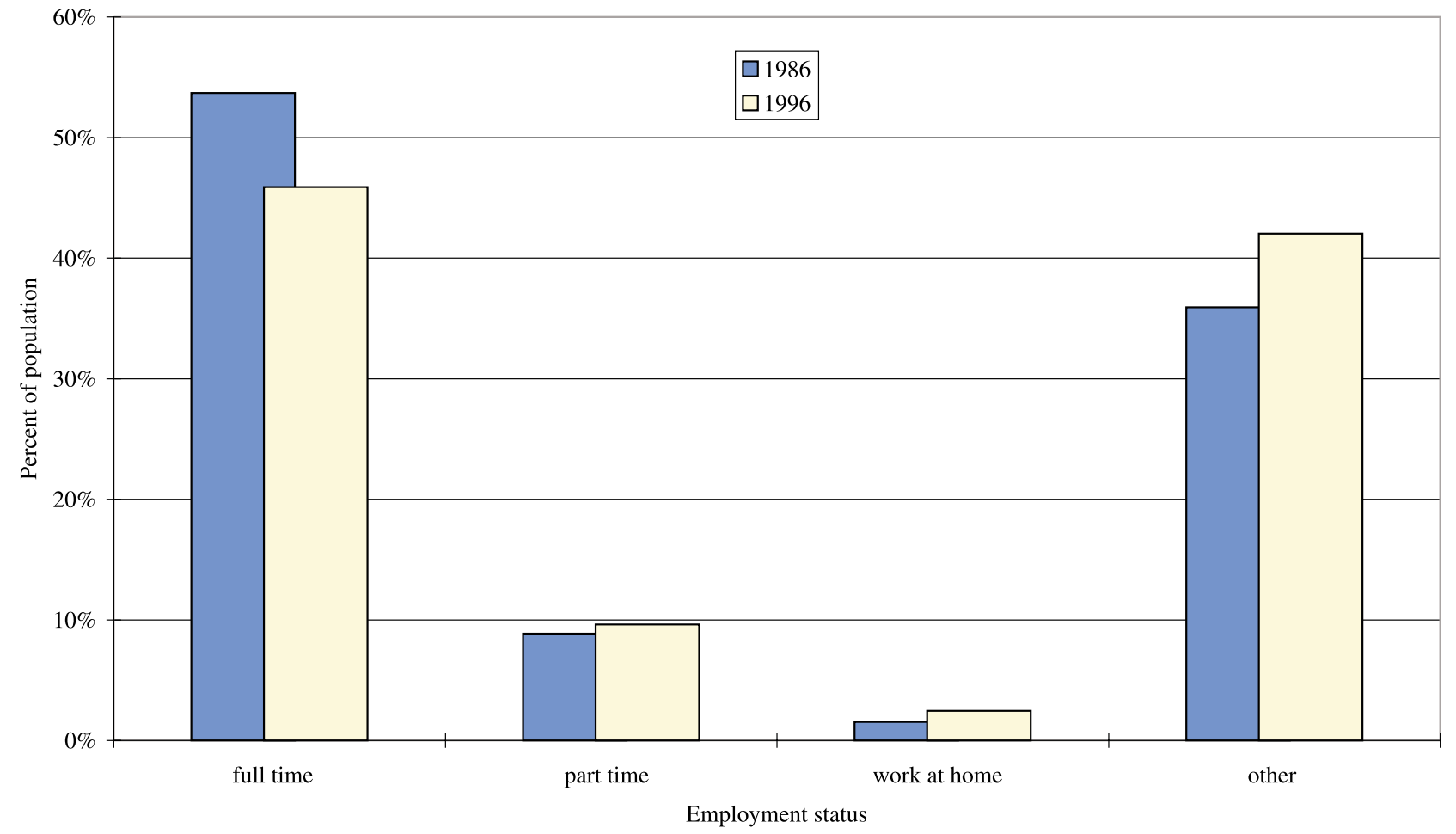

(2) home-based discretionary trips increased substantially from both population growth and trip rate change; (3) increase in home-based work trips from population growth was mitigated by change in trip rate; (4) both population growth and overall trip rate change resulted in substantial increases in auto-driver trips and to a lesser degree autopassenger trips; and (5) the gain in transit trips from population growth was counteracted by the shift in population composition, resulting in a net loss in transit trips.

Table 1 shows that the shift in employment status distribution resulted in the largest change in the total number of trips compared with the two other variables. The increase in the proportion of non-workers reduced greatly the number of home-based work trips in both periods and the number of non-home-based trips, whereas it increased the numbers of home-based school and home-based discretionary trips. Other major changes in trips by purpose associated with the individual changes in the three distributions include the reduction in home-based school and the increase in homebased discretionary trips associated with the age distribution shift (i.e., the reduced proportion of young persons).

With respect to changes by travel mode, the shift in the employment status distribution resulted in the largest change, reducing the number of auto-driver trips by nearly 0.35 million. The individual shifts of both age and residential location distributions resulted in a substantial increase in the number of auto-driver trips. While population aging resulted in a decline in the number of auto-passenger trips be- 
Fig. 13. Trip rate by employment status.

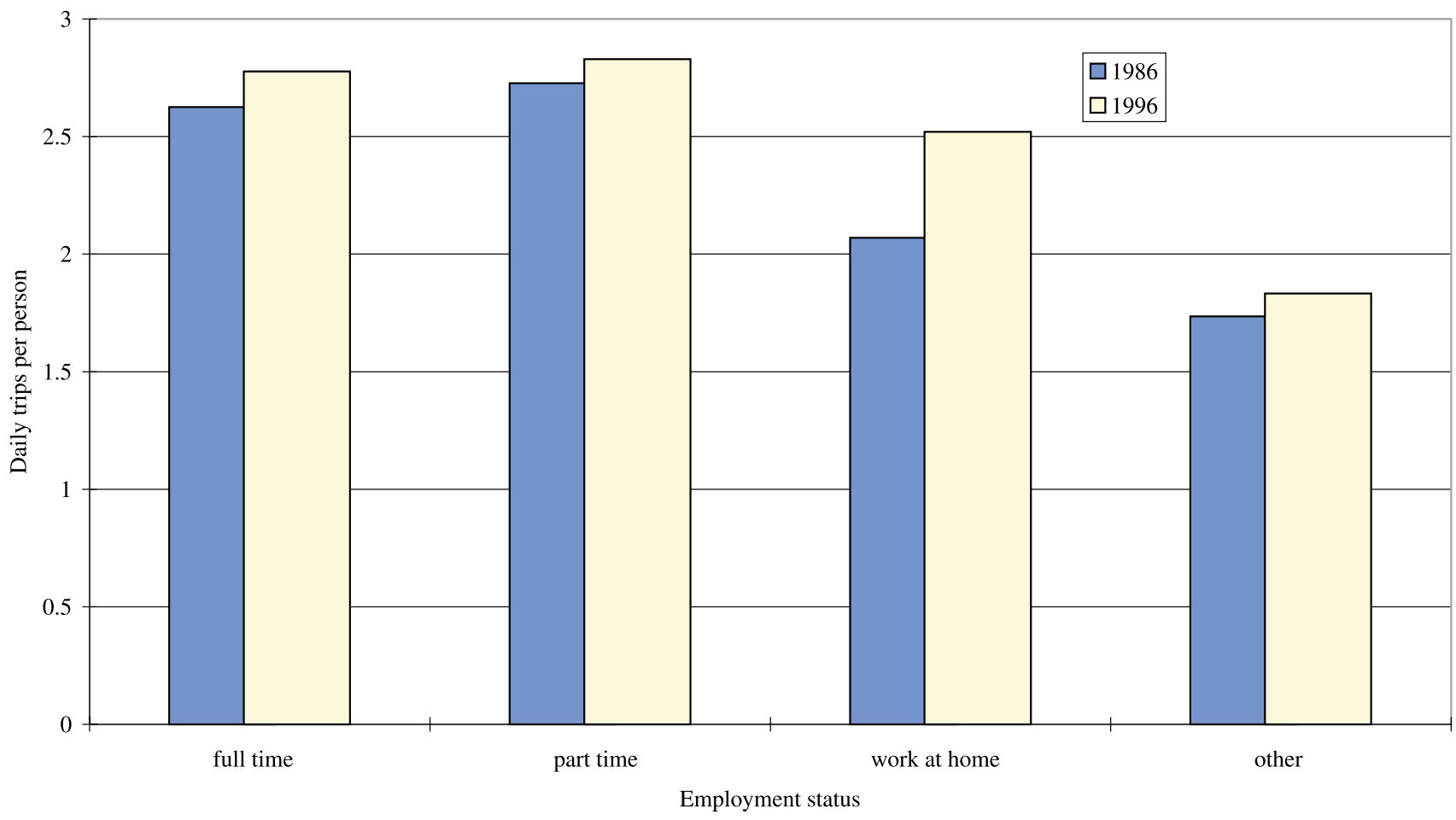

Fig. 14. Travel changes due to shift in employment status distribution.

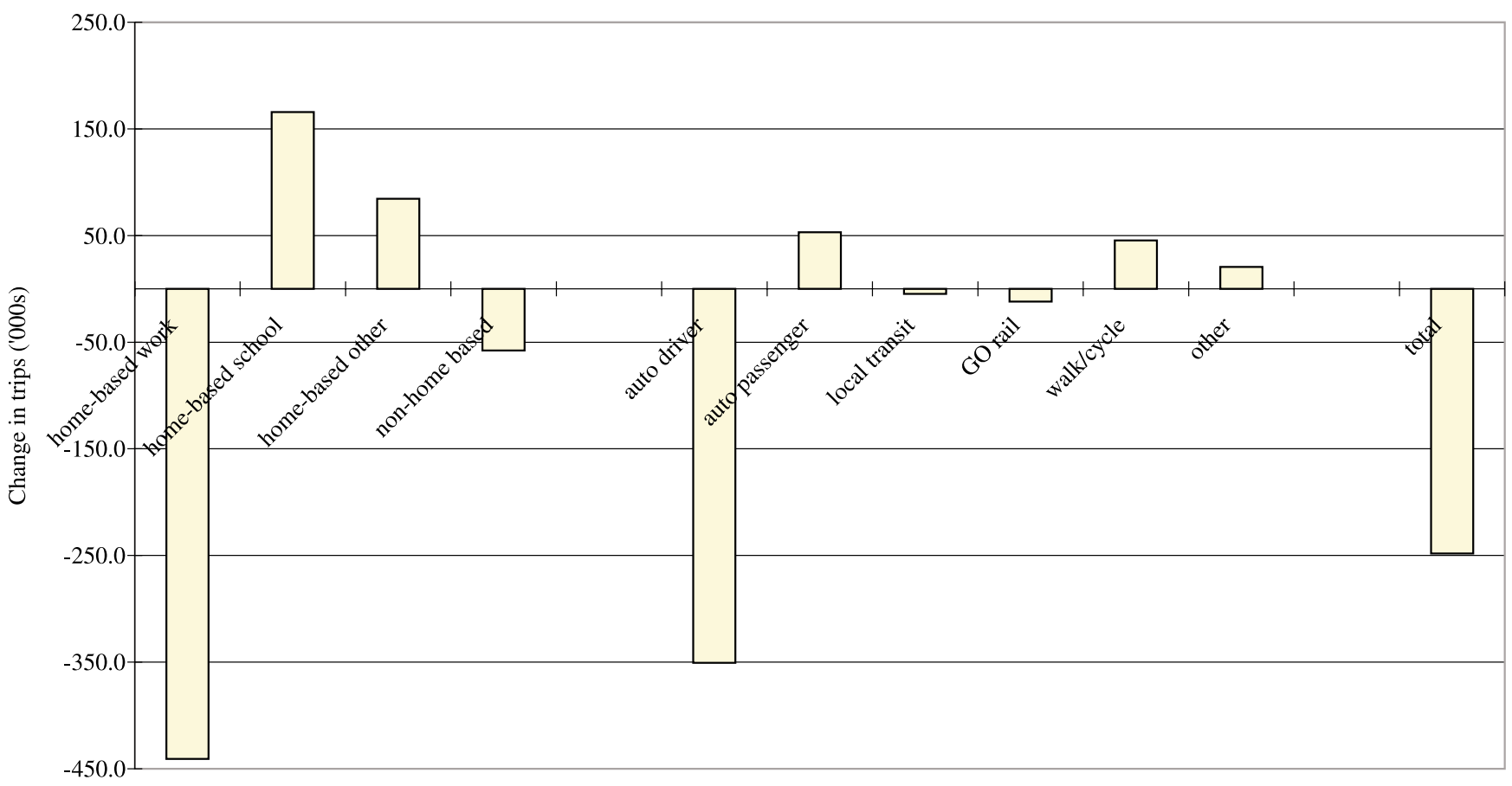

tween 1986 and 1996, the increased proportion of nonworkers resulted in an increase in the number of these trips during the same period. The changes in the number of walkcycle trips followed the same pattern as that of the number of auto-passenger trips.

Urban sprawl (i.e., shift in residential location distribution), and to a slightly lesser degree population aging, contributed greatly to the reduction in the number of transit trips in the 10-year period from 1986 to 1996 . The shift in the employment status distribution had a much less significant effect on the number of transit trips.

\section{Implications for future travel}

The analysis in this paper shows that the aging of the population has resulted in increased auto-driver trips and re- 
Table 1. Summary of trip changes $(\times 1000)$ between 1986 and 1996 in the Greater Toronto Area.

\begin{tabular}{|c|c|c|c|c|c|c|}
\hline \multirow[b]{2}{*}{ Component } & \multicolumn{2}{|c|}{$\begin{array}{l}\text { Change in travel } \\
\text { associated with: }\end{array}$} & \multirow[b]{2}{*}{$\begin{array}{l}\text { Overall } \\
\text { change } \\
\text { in travel }\end{array}$} & \multicolumn{3}{|c|}{$\begin{array}{l}\text { Change in travel associated with } \\
\text { shift in distribution of: }\end{array}$} \\
\hline & $\begin{array}{l}\text { Population } \\
\text { increase }\end{array}$ & $\begin{array}{l}\text { Trip rate } \\
\text { change }\end{array}$ & & Age & $\begin{array}{l}\text { Residential } \\
\text { location }\end{array}$ & $\begin{array}{l}\text { Employment } \\
\text { status }\end{array}$ \\
\hline \multicolumn{7}{|l|}{ Trip purpose } \\
\hline Home-based work & 617 & -282 & 335 & 1 & 22 & -441 \\
\hline Home-based school & 207 & 37 & 244 & -156 & 11 & 166 \\
\hline Home-based other & 566 & 419 & 984 & 106 & 28 & 85 \\
\hline Non-home based & 222 & 129 & 351 & 28 & 11 & -58 \\
\hline \multicolumn{7}{|l|}{ Travel mode } \\
\hline Auto driver & 970 & 355 & 1326 & 147 & 149 & -351 \\
\hline Auto passenger & 227 & 200 & 427 & -40 & 19 & 53 \\
\hline Transit & 257 & -287 & -30 & -74 & -99 & -5 \\
\hline GO rail & 12 & 18 & 30 & 0 & 7 & -12 \\
\hline Walk-cycle & 109 & 14 & 123 & -44 & -14 & 45 \\
\hline Other & 36 & 3 & 39 & -10 & 11 & 21 \\
\hline Total & 1612 & 303 & 1915 & -21 & 72 & -248 \\
\hline
\end{tabular}

duced transit, auto-passenger, and walk-cycle trips. Those of the "baby boom" generation are now between their mid-30s and mid-50s, which corresponds to the highest age range with respect to auto-driver trip rate. Although the "baby boom echo" generation has the potential to reverse the above trends associated with the aging of the population, it will take at least one decade until the last "baby boomer" is older than the age group with the highest auto-driver trip rate. By that time, the baby boom echo generation will reach the age of the highest auto-passenger and transit trip rates. Therefore, it is expected that the above trends associated with the aging of the population between 1986 and 1996 will continue for the next decade.

Urban sprawl, as indicated in the shift in residential location distribution, between 1986 and 1996 resulted in increased auto-driver trips and reduced transit trips. There is no indication that this urban sprawl is changing course. Unless public policy mitigates urban sprawl, the associated trends of more travel by auto and less travel by transit are expected to continue in the future.

The declining economy between 1986 and 1996, as reflected in the changed employment status distribution, caused a large reduction in the number of auto-driver trips and an increase in the number of auto-passenger and walkcycle trips. As the economy is currently picking up, the number of auto-driver trips is expected to increase in association with such changes.

In summary, although transit ridership may experience growth in the next decade due to population growth, changes in other factors are expected to counter that increase. On the other hand, auto travel is expected to grow because of popu- lation increase and changes in other factors such as improved economy, population aging, and urban sprawl.

Other factors can be investigated individually using the approach developed in this paper, and relevant implications can be drawn similar to those of the discussion presented here.

\section{Acknowledgements}

The funding of this study by the Natural Sciences and Engineering Research Council of Canada (IRF Program), the University of Toronto Joint Program in Transportation, and IBI Group is greatly appreciated.

\section{References}

Akiva, M.B. 1974. Structure of passenger travel demand models. Transportation Research Record 526, pp. 26-42.

Pickrell, D., and Schimek, P. 1997. Trends in personal motor vehicle ownership and use: evidence from the nationwide personal transportation survey. In Proceedings of the Nationwide Personal Transportation Survey Symposium. U.S. Department of Transportation, Bethesda, Md., 29-31 October 1997. pp. 85-127.

Shalaby, A. 1998a. Investigating the role of relative level-ofservice characteristics in explaining mode split for the work trip. Transportation Planning and Technology, 22(2): 125-148.

Shalaby, A. 1998b. Exploring trends in the Greater Toronto Area - Part 1: changes in travel-related factors and implications for travel demand. Joint Program in Transportation, University of Toronto, Toronto, Ont.

Shalaby, A. 1998c. Exploring trends in the Greater Toronto Area Part 2: changes in travel and relationship with factors. Joint Program in Transportation, University of Toronto, Toronto, Ont. 